\title{
Early Materials Launched Modern-Day Spacecraft Capabilities
}

Materials used to construct spacecraft have their roots in early rocketry, which most scholars agree can be attributed to early Chinese inventors. The fuel for early rockets was gunpowder. Its first recorded use is found in a recipe from the $W u$ Ching Tsung Yoa, circa 1040 A.D. The ancient Chinese manuscript T-hung-lian$k a n g-m u$ refers to the first use of rockets in 1232 A.D., during a siege laid to the South China city of Kai-Fung-Fu by the Mogul hordes led by Ogdai, son of Ghengis Khan.

In 1240 , eight years after the battle of Kai-Fung-Fu, an anonymous scholar described the use of saltpeter, a naturally occurring form of potassium nitrate, known as the "snow of China." Saltpeter, along with sulfur and charcoal, was a key ingredient in making gunpowder. Another anonymous scholar referred to these gunpowder-fueled rockets as "Chinese arrows."

The craft of rocketry evolved slowly. One reason for this slow growth was the instability of gunpowder, which tended to explode before it was expected to. At the beginning of the nineteenth century, an officer in the British Royal Artillery, William Congreve, discovered that gunpowder moistened with alcohol could be hammered safely without igniting. His work allowed rockets to achieve ranges of up to 2,000 meters. But even with this newfound stability for gunpowder, rockets were limited to lightweight, high-performing weapons that could not compete with the accuracy and explosive power of artillery charges until the invention of the liquid-fueled rocket.
On March 16, 1926, the space age began when Robert Goddard launched a small liquid-fueled rocket for a short but tremendously significant flight. With the start of World War II, the pace of rocket science began to accelerate: Germany tested a 14-ton V-2 rocket, launched on October 3, 1942, only 16 years after Goddard's first flight; fifteen years later, on October 4, 1957, the Soviet Union launched Sputnik into Earth orbit; and twelve years after that, on July 22, 1969, U.S. spacecraft landed on the Moon. But these astonishing successes were not without difficulties.

The materials for propulsion presented a major problem with early rocketry, specifically erosion of the engine nozzle by hot exhaust gases. Exhaust gases from the combustion process in the engine had to be channeled through a properly contoured nozzle so as to control the thrust. The nozzle had to be highly resistant to any thermal expansion or erosion that would change the size or shape of the nozzle opening, so as to prevent modification of the burning characteristics of the propellant. Thus, the nozzle was required to be temperature resistant, light in weight, erosion and thermal shock resistant, with high structural strength. An early choice of material was graphite, which was widely-used and permitted the evolution of early liquid-fueled rockets.

In Germany, in 1942, graphite was also used for the exhaust vanes in V-2 rockets. Because of graphite's susceptibility to oxidation, as well as its tendency to erode due to the metal additives in solid propellants, graphite was replaced by other materials, such as molybdenum, silicon nitrate, and tungsten. By the 1950s, another material, boroaluminosilicate fibrous glass-reinforced plastic, was being used to construct high-pressure solid propellant rocket motor casings. Such reinforced plastic casings were significantly more lightweight than earlier ones.

Reinforced plastic was not only used for launching mechanisms, but also was applied to space capsules, recovery gear, structural parts, dielectrics, electrical insulation, and reentry bodies. For example, during reentry a number of schemes for thermal protection were used such as ablation, radiation cooling, high-temperature parachutes, inflated drag brakes, inflatable lifting surfaces, or a combination of these. Ablative designs used plastics that chemically changed their composition and sublimed when they were heated.

Present advanced technology initiatives such as the National AeroSpace Plane, a joint Department of Defense-NASA project to field a Single-Stage-To-Orbit spacecraft that can take off from a runway and accelerate to space, are spearheading programs in materials science to encourage further advances in this area.

DOUG BEASON

For Further Readinc: Earl R. Parker, ed., "Materials for Missiles and Spacecraft," (McGraw-Hill, New York, 1963); Canby Courtland, A History of Rockets and Space (Hawthorn, New York, 1963); Spacecraft Design and Operational Problems; Aerospace Technology Conference, 1985 (Society of Automotive Engineers, Warrendale, PA, 1986).

\section{Fluorine-Carbon and Fluoride- Carbon Materials T. Nakajima, editor} (Marcel-Dekker, New York, 1994, 416 pages, $\$ 165.00$ ) ISBN: 0-8247-9286-6

Fluorine-Carbon and Fluoride Carbon Materials, edited by Tsuyoshi Nakajima, is an excellent and authoritative reference work dealing with fluorine graphite intercalation compounds (GIC's), main- group and transition metal fluoride GICs, $\mathrm{B} / \mathrm{C} / \mathrm{N}$ analogues of GICs, fluorinated fullerenes, carbon and modified carbon anodes for elemental fluorine production, and the relatively new superhydrophobic nickel-tetrafluoroethyleneoligiomer composites. The list of contributors is a literal "who's who" of recognized experts in their various fields, including Neil Bartlett, Marius Chemia, Yong-Bo Chong, Didier Devilliers, Mildred S. Dresselhaus, Morinobu Endo, Rika Hagiwara, John H. Holloway, Jean-Paul Issi, Masayuki Kawaguchi, Tsuyoshi Nakajima, Tetsuro Tojo, Alain Tressaud, Yuko Tsuya, and Rachid Yazami. The authors, in their 